\title{
Choice Modelling of a Car Traveler towards Park-and-Ride Services in Putrajaya to Create Green Development
}

\author{
Irfan Ahmed Memon ${ }^{1,2,3, * \mathbb{C}}$, Noman Sahito ${ }^{1}\left(\mathbb{D}\right.$, Saima Kalwar ${ }^{1}$, Jinsoo Hwang ${ }^{4, *}{ }^{\mathbb{D}}$, Madzlan Napiah ${ }^{2}$ \\ and Muhammad Zaly Shah ${ }^{3}$ (i)
}

1 Department of City \& Regional Planning, Mehran University of Engineering \& Technology, Jamshoro 76062, Pakistan; nauman.sahito@faculty.muet.edu.pk (N.S.); saima.kalwar@faculty.muet.edu.pk (S.K.)

2 Department of Civil \& Environmental Engineering, Universiti Teknologi PETRONAS, Seri Iskandar 32610, Malaysia; madzlan_napiah@utp.edu.my

3 Department of Urban \& Regional Planning, Faculty of Built Environment, Universiti Teknologi Malaysia, Skudai 81310, Malaysia; b-zaly@utm.my

4 College of Hospitality and Tourism Management, Sejong University, 98 Gunja-dong, Gwanjin-gu, Seoul 143-747, Korea

* Correspondence: irfan.ahmed@faculty.muet.edu.pk (I.A.M.); jhwang@sejong.ac.kr (J.H.)

\section{check for} updates

Citation: Memon, I.A.; Sahito, N.; Kalwar, S.; Hwang, J.; Napiah, M.;

Zaly Shah, M. Choice Modelling of a Car Traveler towards Park-and-Ride Services in Putrajaya to Create Green Development. Sustainability 2021, 13, 7869. https://doi.org/10.3390/ su13147869

Academic Editors: Codruta

Adina Baltescu and Aurelia Felicia Stancioiu

Received: 25 May 2021

Accepted: 11 July 2021

Published: 14 July 2021

Publisher's Note: MDPI stays neutral with regard to jurisdictional claims in published maps and institutional affiliations.

Copyright: (c) 2021 by the authors. Licensee MDPI, Basel, Switzerland. This article is an open access article distributed under the terms and conditions of the Creative Commons Attribution (CC BY) license (https:/ / creativecommons.org/licenses/by/ $4.0 /)$.

\begin{abstract}
Putrajaya is facing an increasing number of private car ownership and its usage. Integrated transportation infrastructure connecting the city with suburban areas and comparatively low-cost housing schemes are at the fringes of Putrajaya City. It creates a discrepancy between housing and employment attentiveness. Due to the attractiveness of jobs in the city centre, commuters' travelling pattern is morning/evening peak hours, and it leads to traffic congestion on a few major artilleries leading to and from the city. In contrast, Putrajaya was designed to achieve a 70:30 modal split ratio. This policy was introduced to target $70 \%$ of the commuters towards a sustainable mode of transport as their mode choice. Currently, congestion in Putrajaya is due to the use of singleoccupant vehicles (SOV). The SOV users cannot be convinced to use the park-and-ride services (P\&RS) without understanding their travel behaviors. Therefore, the mode choice models (MCM) were developed through binary logit regression (BLR) approaches to determine the factors that influence the SOV travelers' decisions to adopt the P\&RS. As a result, several factors, which included the socio-demographic factors, travel time, travel expenses, environmental protection, avoiding stress, parking problems, vehicles sharing, and traveling directly, were found to be significant and will promote green development. Furthermore, the quality of the developed mode choice model was validated through the training and testing approach of logistic regression. Ultimately, this study can help stakeholders to encourage SOV users towards P\&RS by overcoming these factors.
\end{abstract}

Keywords: park-and-ride service; mode choice model (MCM); travel behavior; single occupant vehicle (SOV); binary logit regression (BLR); Putrajaya; green development

\section{Introduction}

Mobility is a critical challenge for developing cities because it is separate from health, schooling, and accommodations [1,2]. For instance, according to the Interesting Engineering media report the average driver in Mexico City spends $218 \mathrm{~h}$ each year sitting in traffic. This means, if a person works for 35 years, they would be spending more than 315 days stuck behind the wheel. That is almost a year of one's life [3]. Consequently, mobility continues to worsen as economies become richer and unsustainable. Mobility is the question of equality and equity instead of money and technology. It is difficult to observe the inequality in developing nations. For example, when it comes to travel, a developed country is not a location where the poor owns cars, it is a location where the wealthy use public transportation. In Amsterdam, 30\% of the inhabitants use bicycles, even though Holland has a high average income [2]. 
Over the last few years, the trend regarding trip generation has increased substantively [1]. This has increased the use of private cars and congestion, so pollution has increased. Owing a car is a feeling of pride, independence, status, and honor. Additionally, it provides a sense of supremacy and dominance [4,5]. Moreover, the affirmative use of a single occupant vehicle (SOV) is reliant on the travelers' way of living and their socialspatial engagements [6]. Some suggestions have recommended that specific SOV travelers do not travel out of need. They travel because of their choice [7]. Therefore, it is mandatory to introduce approaches that can reduce the dependency on private cars by introducing sustainable alternative modes of choice, such as bicycling and walking. Additionally, it is mandatory to promote initiatives that can reduce the dependency on the SOV $[1,8,9]$.

The densely populated structure and mixed land-use features in Asian cities are following the urban sprawl development of western countries and developing their highways, expressways, and rapid transit system [10]. A 20-year period of study by the University of Toronto in different cities revealed that expansion of road network by $10 \%$ also increases congestion in that city by $10 \%$ [11]. Actions on the way to lessen long-term traffic jamming cannot depend upon the implementation of public transportation alone as the light rail, in addition they must set up park-and-ride ( $P \& R)$ and other travel demand management strategies [12]. When executed efficiently, the P\&R service can be one of the few elective strategies that would be the response to settling the issue of traffic jamming and bringing long-term relief [13].

The utilisation of P\&R service is influenced by various factors, such as the facility of public transportation, the circumstance of the parking lot, and parking area quality [14]. Other depending factors include the choice of time and price savings associated with travelling by car for the entire trip. It is related to previous results that the willingness of car travellers to use $P \& R$ service is enhanced when the travel time of using $P \& R$ service is minimal [15]. To propose minimal travel time by $P \& R$ service, there is a need to introduce dedicated bus lanes to the city centre and allow a dynamic shift at the $P \& R$ service which will possibly consume minimum travel time. Furthermore, Hamid et al. [16] described that it is essential to save money and also time to use P\&R service in comparison to other modes of transport.

\section{Study Area}

Malaysia's new federal administrative capital at Putrajaya is a different Malaysian city from a transportation policy perspective. Putrajaya has an explicit policy goal to achieve a 70 percent share of all travel done using an alternative sustainable mode choice to its main precincts $[17,18]$. Putrajaya has a prominent status, known as the world's first intelligent Garde City [18]. Putrajaya's design is a strong, inspiring, and sustainable human development that has met the rising needs in the country for at least 300 years [18]. The excessive use of private vehicles and the rapid traffic rise is a more significant concern for this city [1,19]. Correspondingly, the park and ride service (P\&RS) tends to be a good alternative to vehicles. However, very few commuters use the P\&RS [20-25], even though the tasks confronting the city authority seem unlikely due to the purpose requiring the reversal of the existing 15:85 modal split between public and private transportation $[17,26]$. The current modal choices include $70 \%$ for cars, $15 \%$ for motorcycles, and $15 \%$ for public transportation $[17,26,27]$.

Different studies have given proof of the conventional association between $P \& R$ service and its user's travel behavior. It gives assurance that $P \& R$ service can reduce the traffic flow intensity using public transport in routine trips. As in many types of research on travel behaviors, the trip purpose is considered as an essential variable to understand travel behavior. Lam et al. 2011 recognised that workplace trip makers are major clients of $P \& R$ service in their researches [28]. M.N. Borhan in 2011 found that the P\&R lot at precinct one in Putrajaya was only $2 \%$ occupied and $98 \%$ of lots were vacant and the total capacity number of lots was 320 [19]. 
Different studies were conducted on Putrajaya P\&R service; most of them are described in Table 1.

Table 1. Previous studies on Putrajaya P\&R service.

\begin{tabular}{|c|c|}
\hline S. No. & Research \\
\hline 01. & $\begin{array}{l}\text { Title: Predicting the Use of Public Transportation: A Case Study from Putrajaya, Malaysia } \\
\text { Summary: To understand commuters' choice to utilise public transport, a conceptual model has been created to decide } \\
\text { the variables that influence them to utilise public transport as opposed to going in their vehicles. Different factors, such } \\
\text { as; quality, environmental effect, attitude, and behavioural intentions were examined and tested through the structural } \\
\text { equation model (SEM). More research in the future ought to be led to discover the effect of attributes concerning } \\
\text { financial hindrances, for example, traffic congestion charges to urge individuals to utilise public transportation in } \\
\text { Putrajaya [24]. }\end{array}$ \\
\hline 02 & $\begin{array}{l}\text { Title: Evaluating the Parking Demand at P\&R Facility at Putrajaya Public Transportation Terminal } \\
\text { Summary: This study analysed two types of parking usability; multi-story and surface parking at Putrajaya public } \\
\text { transportation terminal. It is important to analyse the demand for P\&R service to know the current usage of P\&R } \\
\text { facility as well as the travel behaviour of the parking users [25]. }\end{array}$ \\
\hline 03 & $\begin{array}{l}\text { Title: Awareness and level of usage for P\&R facilities in Putrajaya, Malaysia } \\
\text { Summary: This contextual investigation was to decide the travellers' attention towards P\&R service in Putrajaya, to } \\
\text { evaluate the level of utilisation of P\&R facilities at Putrajaya, and to recognise the nature of duty for P\&R facilities at } \\
\text { Putrajaya. Along with the improvement of amenities and bus services, more information about P\&R services should be } \\
\text { spread [21]. }\end{array}$ \\
\hline 04 & $\begin{array}{l}\text { Title: Users' Perceptions on Parking Utilization Pattern at P\&R Facility in Putrajaya Sentral } \\
\text { Summary: This Research founds the users' discernments on parking utilisation behaviour at Putrajaya Central P\&R } \\
\text { service. Surface parking services must be affordable for travellers, monthly parking tickets, parking charges, and smart } \\
\text { card payment system and promotion must be introduced [29]. }\end{array}$ \\
\hline 05 & $\begin{array}{l}\text { Title: Prediction of Traveling Behaviour in Putrajaya, Malaysia } \\
\text { Summary: In this study, the viability of P\&R service at Putrajaya region was examined. This examination led to a } \\
\text { decrease in the utilisation of private vehicles is to replace SOV users' trips with different modes of transport. Such as a } \\
\text { mix of a private vehicle and public transport called P\&R service. Increasing parking charges at the workplace would } \\
\text { decrease the usage of private vehicle users [19]. }\end{array}$ \\
\hline 06 & $\begin{array}{l}\text { Title: Effect of Transport Policies to Shifting Private Car Users to P\&R in Putrajaya, Malaysia } \\
\text { Summary: This research is to inspect the variables which have an impact on SOV users and presenting a few new } \\
\text { approaches (dedicated bus lane and high parking price at the workplace) to switch towards P\&R service in Putrajaya. } \\
\text { The discoveries were examined time, and cost-saving is the relevant variables to impact SOV users to utilise P\&R office. } \\
\text { The behavioural sciences hypothesis in particular Theory of Planned Behaviour (TPB) will be utilised as a part of } \\
\text { comprehension and distinguish the affecting variables to shifting private transport users to adopt P\&R service [30]. }\end{array}$ \\
\hline 07 & $\begin{array}{l}\text { Title: Predicting the Impact of Demand-and Supply-Side Measures on Bus Ridership in Putrajaya, Malaysia } \\
\text { Summary: This study portrays and discusses the techniques, results, and policy consequences of the research. } \\
\text { Econometric estimation demonstrates that improvement in public transportation alone is an inadequate modal choice to } \\
\text { accomplish the objective of a 70:30 modal split among public and private transportation [22]. }\end{array}$ \\
\hline
\end{tabular}

This study aims to investigate the measures that affect the modal split of the travelers to switch to the P\&RS. In this study, an ANN's MLP approach was adopted to develop a mode choice model, and the use of the model was described in this research. Therefore, it is important to explore SOV users' travel habits and the willingness to change the mode if given positive encouragements. The results are beneficial for policymakers and stakeholders.

\section{Park and Ride Service}

The P\&R service involves parking services at commute stations, bus stops, and on roads, and they are on the edges of the city to make the use of P\&R services smoother. Parking is normally free or comparatively cheaper than it is downtown [31,32]. The P\&RS can increase commuting and ridesharing trips. Turnbull et al. examined the impacts of the P\&RS on the transport network [33]. Morrall and Bolger determined that the stipulation of 
the P\&RS has a major influence on the downtown areas' transit trips that are made by the passengers [34,35].

Traffic jams and the use of SOVs are extensively involved with each other. To alleviate road congestions, two techniques exist. One is to deter the use of SOVs, and the another is to encourage the use of a sustainable alternative mode of transportation [36]. Figure 1 illustrates how these objectives relate to the wider accepted provisions for individual travel reductions [37]. P\&RS has significant outcomes regarding the accomplishment of a transit framework [38].

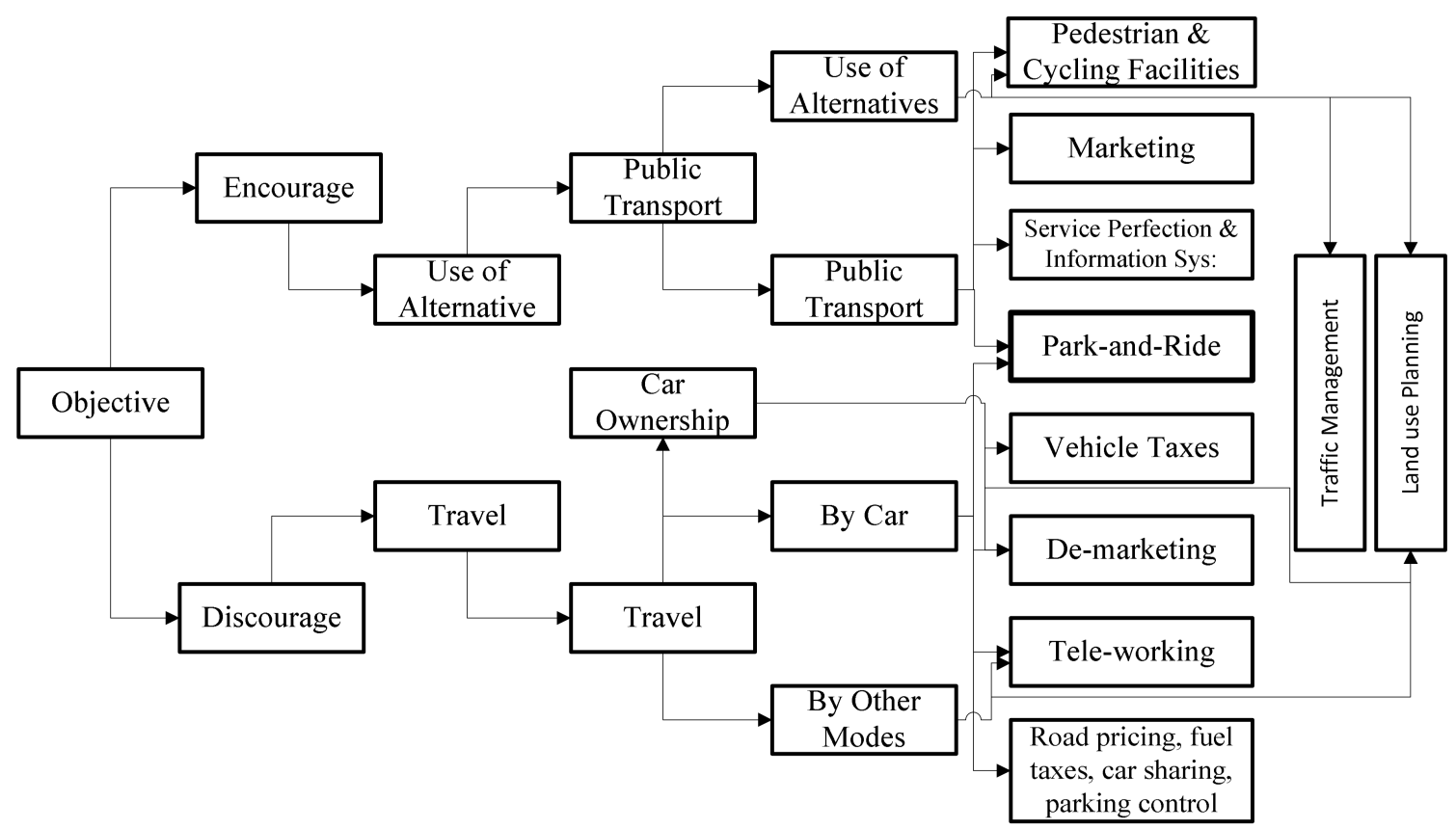

Figure 1. The role of $P \& R$ in car travel reduction.

\section{Influencing Factors Mode Choice}

The literature elaborates that different factors may influence the individual for their mode choice. Similarly, the factors that are highly influenced include the climates and geography. In this subsection, the different factors are categorized and defined by their influences [39].

The transportation-specific factors, which include expensive parking and a decrease in the commuting time by adopting public transportation, are also known as the key factors which influence the use of the P\&RS [29].

It was revealed that the main factors that influenced the P\&RS users included avoiding traffic congestion, convenience, a less stressful journey using public transportation, and costly workplace parking [29]. Therefore, to ensure the success of the P\&RS, encourage more SOV users to adopt $\mathrm{P} \& \mathrm{R}$ service while travelling towards the city center $[23,40,41]$.

Individual-specific factors are associated with the travelers' demographic and socioeconomic attributes, which include age, gender, educational level, occupation, employability, household size, monthly income, lifestyles, and social activities [42-44]. The involvement of monetary crises has demonstrated that adjustments in the travel patterns contrast in connection to the family income, the distance, and the mode choices. Lee (2010) illustrated that the most visible changes that involve anxiety with travel for certain purposes and the activities for some individuals no longer exist, or they were essentially reduced, which include work and shopping. The decline in the transportation demand influenced both the private and the public transportation modes. People balanced their travel behavior with a specific objective to decrease the expenses that are dedicated to transportation, and 
the acknowledgment of the sustainable mode of transportation appeared to be higher among the younger age groups and the higher pay classes [42].

Attitude is considered as a sort of evaluative reaction, which is a liking or a disliking, towards a specific aim. It is also underlined as a mediating factor in a social psychology study and as a theoretical development, which can be induced but cannot be specifically examined [24]. Similarly, the study of travel behavior is not affected by the transportation service, but it is impacted by the psychological components, which include observations, states of mind, and habits [45,46]. As indicated by Fishbein and Ajzen (1980), attitude towards the travel behavior imitates the entire assessment of the execution of a pattern by the travelers in the theory of planned behavior (TPB). Attitude is dependent on the hope of the convictions about the probability that the behavior will bring about specific outcomes and on the assessments of the attractiveness of those significances [47]. The application of the concept recommended that the system quality and the fundamental concerns will be connected using the behavior towards public transportation. Additionally, there are also other substitute models, which include the service quality and the environmental factors, that might specifically influence the behavioral aim in this study [24].

Previously, the influence of the psychological factors was indirectly tested using the latent variable approaches by applying the hybrid choice models (HCM). The influence of the attitudes to walking and cycling on a travel mode choice through the HCM was explored by [48]. The role of the psychological factors through the HCM approach revealed that the indirect effect of the social aspects on the modal split is obtained [49]. The psychological factors and consolidating the time-use and a travel pattern for a traveler's psychological and physical wellbeing attributes are included within the developing nation context [50].

\section{Research Methods}

This research is based on mode choice modelling, which follows the research flow. This methodological flow is further distributed into three phases according to the nature of the research methodology, as shown in Figure 2. The study starts with the present situation of the urban transportation framework in the study areas. Phase one is a pre-analysis, which is also known as the preliminary phase. Phase two is technical analysis, and the third phase is the post-analysis phase. The details of the three phases are shown below in the research process diagram. This research depends on the primary information. The primary data were collected using a self-administered questionnaire.

The primary data were collected using two different groups of travelers in the study areas. One group is the users of the P\&RS, and the second group is the non-users of the P\&RS. Specifically, the private transportation users were the main focus group of the study. Both groups, which include the car travelers and the P\&RS users, were focused on completing the self-administered survey questionnaires. The questionnaires were filled out physically at the workplace and by using a Google Form approach to meet the demand. The research survey used both the revealed and the stated preference approaches.

The technical analysis phase discusses the modelling of the data. The binary logistic modelling approach was applied to develop the mode choice model. Furthermore, this model was validated through training and testing of the logistic regression approach [9]. 
Pre-Analysis Phase

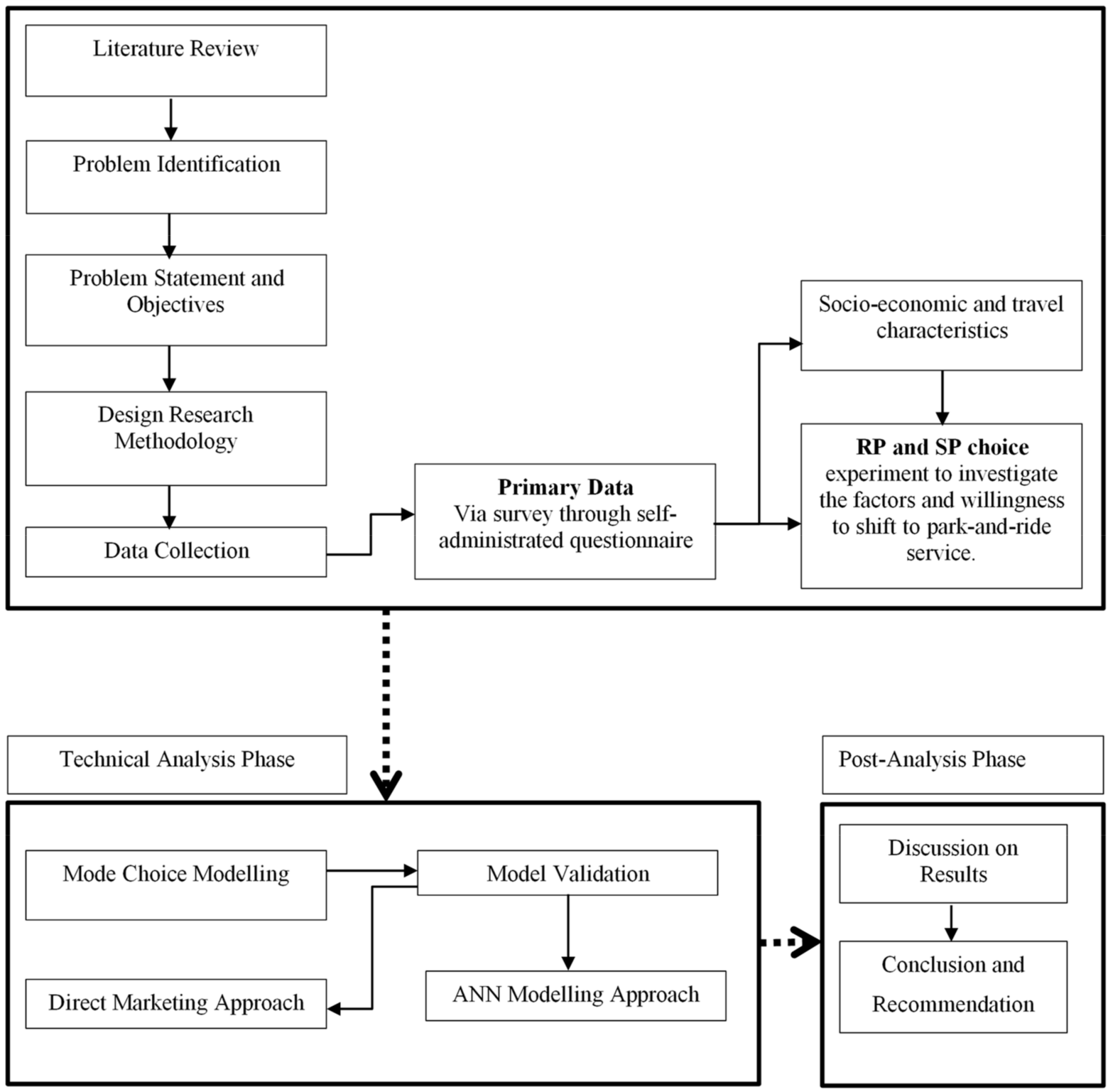

Figure 2. Research process diagram.

\section{Study Variables}

This research focused on the travel behavior of the travelers to develop a mode choice model to shift the car travelers towards the P\&RS. The travel behavior addresses the factors that influence the users and the non-users of the P\&RS. According to the literature, which was discussed in the previous section, this study includes the socio-demographic, environment, trip, transport, quality, attitude, and the uncertainty specific factors, which are described in Table 2. 
Table 2. Study factors and their variables with codes.

\begin{tabular}{|c|c|c|c|c|c|c|}
\hline Socio-Demographic & Environment & Trip & Transport & Quality & Attitude & Uncertainty \\
\hline \multicolumn{7}{|c|}{ Specific Factors with Codes } \\
\hline $\begin{array}{c}\text { Gender } \\
\text { Monthly Income (MI) } \\
\text { Educational level (EL) } \\
\text { Household size (HS) } \\
\text { Transport ownership (TO) } \\
\text { Job Nature (JN) }\end{array}$ & Harsh weather (HW) & $\begin{array}{c}\text { Travel time per trip (TTPT) } \\
\text { Drop kids (DK) } \\
\text { Drop family member (DF) } \\
\text { Going shopping (GS) } \\
\text { Travel directly (TD) } \\
\text { Travel expenses (TE) } \\
\text { Workplace Distance (WD) } \\
\text { Effect of travel time (ETT) } \\
\text { Trips per day (TPD) }\end{array}$ & $\begin{array}{c}\text { Mode of travelling (MT) } \\
\text { Frequency of Bus (MB) } \\
\text { Improper location of P\&R (ILP\&R) }\end{array}$ & $\begin{array}{c}\text { Comfort preference (CP) } \\
\text { Expensive parking at workplace (EPW) }\end{array}$ & $\begin{array}{c}\text { Personal status (PS) } \\
\text { Privacy } \\
\text { Car is convenient (CC) }\end{array}$ & $\begin{array}{l}\text { Safety and security at P\&R (SSP\&R) } \\
\text { The threat of terrorism/violence (TTV) } \\
\text { The threat of robbery/snatching (TRS) }\end{array}$ \\
\hline
\end{tabular}


In particular, the specific factors include gender, income, educational level, household size, transport ownership, and job nature. The environment-specific factors include harsh weather. Similarly, a trip contains the travel time per trip, vehicle sharing, dropping off children, dropping off family members, shopping, traveling directly, travel expenses, trip distance, the effect of the travel time, and the trips per day. Furthermore, the transportspecific factors focus on the mode of travelling, the frequency of buses, and the improper locations of a P\&RS station. In contrast, attitude is a modest factor, which contains the personal status, privacy, and cars, that are convenient specific variables. Lastly, quality is also a modest factor, which is comprised of safety and security at the P\&R service, the threat of robberies, and having items stolen. The list of all the variables is shown in Table 1 study factors and their variables. All the factors were considered and tested as the explanatory variables, and their direct impact on the outcome variable was tested.

Furthermore, the influence of the factors and their inputs in the model and research framework is shown in Figure 3. A stated preference (SP) survey has advantages as well as disadvantages. The benefits and the drawbacks of an SP survey rely on an outline and the method that the variables are presented in the questionnaire according to the level of understanding of the respondents (Louviere et al., 2000). The researcher cannot be certain that the respondents behaved as they mentioned in the questionnaire. Therefore, the design of the questionnaire was an essential factor to obtain results that are close to the respondents' behavior. In this research, an experimental design was utilized for the decision experiments. Fractional factorial research allows various scenarios to arise. The major effects expect that all the insignificant factors are considered.

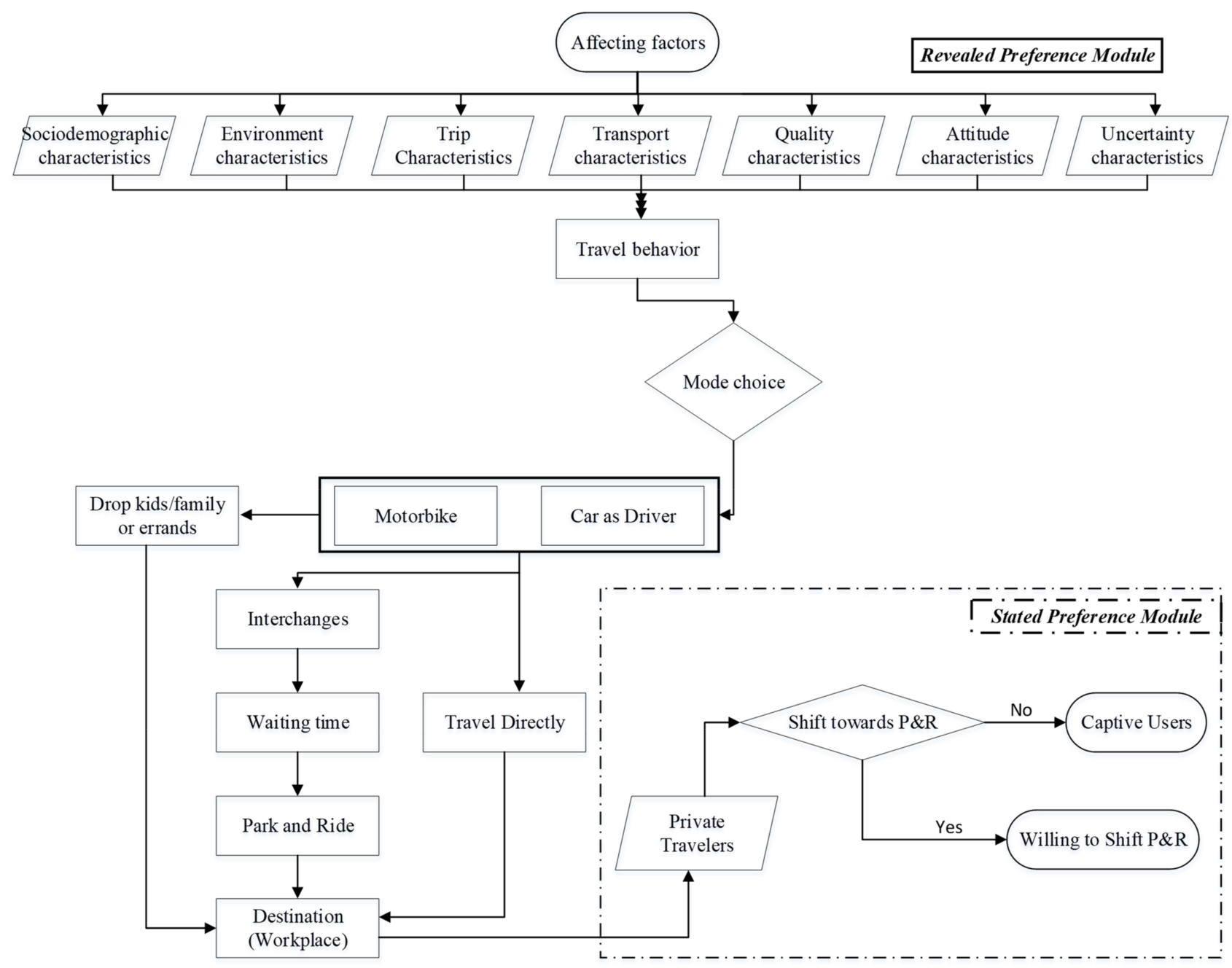

Figure 3. Framework for modelling conducted in this research. 


\section{Results and Discussion}

An approach that combines the revealed preference (RP) and the SP was adopted in this study to model the determining factors that influence the traveler's mode choice. This section first developed a series of models to find the best-fitted model for the collected results from Putrajaya. Several models were prepared for the variables and the travelers' choice to use or not to use the P\&RS by adopting a different combination of the variables. From these models, the best model was selected for the willingness to use the P\&RS, which revealed the best mode for the captive users. Secondly, the chosen model was analyzed and discussed in detail. The discrete choice model approach was adopted, and the Binary logit model was selected on the nature of the data of the travel behavior. In this section, the model development is discussed in detail for the willingness to use and the willingness not to use the P\&RS.

Binary logit modeling is also known as binary logistic regression (BLR) used to examine the relationship between one or more independent (predictor) variables and a single dichotomous dependent (outcome) variable. The purpose of this analysis is to use the independent variables to predict the likelihood that a case is a member of one cluster versus the other (e.g., whether a patient has cancer or not). The binary logistic regression creates a linear combination of all the independent variables to predict the log-odds of the dependent variable. In this computation, the overall significance of the regression model is tested by analysing the $\chi^{2}$ statistic, which is used with the degree of freedom $(d f)$ to calculate the $p$-value (i.e., significance level). A significant overall model implies that the set of predictor variables significantly forecast the outcome variable. If the overall model is significant, the importance of every predictor variable is analysed. An odds ratio $(O R)$ is analysed for every predictor variable and demonstrates the degree to which every predictor variable influences the likelihood that a case is an individual from one outcome cluster versus the other. To conduct a binary logistic regression, the outcome variable must be dichotomous (i.e., there are only two possible outcomes), the observations must be independent of each other, and the association between the predictor variables and the logit-transformed outcome variable must be linear. In economics and transportation binary logit modelling is also known as discrete choice modelling, which means to predict the choice between two alternatives [51].

- $\quad \chi^{2}$ (chi-square test statistic): used with the $d f$ to compute the $p$-value of the overall model.

- $\quad d f$ (degrees of freedom for the chi-square): refers to the number of values used to calculate a statistic; used with $\chi^{2}$ to compute the $p$-value.

- $\quad p$ (probability value): gives the probability of obtaining the observed results if the null hypothesis (no relationship between the independent variable(s) and dependent variable) is right.

- $\quad \beta$ (unstandardized beta): the slope of the predictor with the log-odds of the dependent variable.

- $\quad S E$ (standard error): how much the B is expected to vary.

- $\quad O R$ (odds ratio): gives the factor increase in the likelihood of the dependent variable occurring for every one-unit increase in the predictor; sometimes labelled in statistical output as Exponential $(\beta)$.

- Dummy-code: performed to add a nominal or ordinal predictor variable into the regression model; turns the one variable into a series of dichotomous "yes/no variables. One for each category; one of the categories is left out of the regression as the reference group to which all other groups are compared.

- Nagelkerke $R^{2}$ : measures the goodness-of-fit of the model. It tends to be more conservative than $R^{2}$ values utilised in linear regression models. McFadden $R^{2}$ values of 0.2 or greater indicate an excellent model fit.

- Hosmer and Lemeshow Test: do not need results to be statistically significant, such as 0.05 or below that shows that model is a poor fit. If the value of the result is more than 0.05 , it will reflect that model is a good fit. 


\subsection{Model 1}

The sociodemographic model is designated as Model 1. Model 1 consists of the independent variables, which will be referred to afterward as IVs. These variables included gender, educational level $(E L)$, job nature $(J N)$, household size $(H S)$, monthly income $(M I)$, and transport ownership (TO) method. The BLR was conducted to examine whether the IVs significantly affected the odds of observing the cluster coded as 1 regarding the willingness to switch towards the P\&RS, which is shown in Equation (1). The reference group for the desire to shift was 0 .

$$
\begin{aligned}
& U_{\text {willingness to switch }} \\
& =\beta_{0}+\beta_{1} \times \text { Gender }_{\text {Female }}+\beta_{1} \times \text { Gender }_{\text {Male }} \\
& +\beta_{2} \times E L_{\text {Secondary }}+\beta_{2} \times E L_{\text {Post.Secondary }} \\
& +\beta_{2} \times E L_{\text {Post-Graduation }}+\beta_{2} \times E L_{P h D} \\
& +\beta_{3} \times J N_{(\text {Govt: })}+\beta_{3} \times J N_{(\text {Private })} \\
& +\beta_{3} \times J N_{(\text {Banking })}+\beta_{4} \times H S_{1}+\beta_{4} \times H S_{2-4} \\
& +\beta_{4} \times H S_{5-7}+\beta_{4} \times H S_{>7}+\beta_{5} \times M I_{<R M 1000} \\
& +\beta_{5} \times M I_{<R M 1000-2000}+\beta_{5} \times M I_{R M 2001-4000} \\
& +\beta_{5} \times M I_{R M 4001-6000}+\beta_{5} \times M I_{>R M 6000} \\
& +\beta_{6} \times \mathrm{TO}_{\mathrm{Car}}+\beta_{6} \times \mathrm{TO}_{\text {Bike }}+\beta_{6} \times \mathrm{TO}_{\text {Bike }+\mathrm{Car}}
\end{aligned}
$$

As shown in Table 3, the overall model was statistically significant, $\chi^{2}(8)=25.116$ and $p<0.001$, which suggests that gender, education level, job nature, household size, income, and ownership have a significant effect on the willingness to switch. McFadden's $R$-squared was measured to estimate the model fit. The values greater than $0.2-0.4$ are indicative of models with an excellent fit [52]. The McFadden $R$-squared value calculated for this model was 0.456 . The classification table before the predictive variables were included showed that $60 \%$ of the cases could be accurately arranged by essentially expecting that all the cases were ordered as the willingness to switch. However, after the independent variables were included, the model effectively categorized $82 \%$ of the cases overall. The sensitivity was $69.2 \%$, specificity was $90.6 \%$, the model's positive predictive value was $81.5 \%$, and the negative predictive value was $83 \%$.

Table 3. Logistic regression significant variables of Model 1.

\begin{tabular}{ccc}
\hline Socio-Demographic Factors & $\beta$ & $p$-Value \\
\hline Gender (Male) & 1.751 & 0.001 \\
EL (Post. Sec:) & 0.937 & 0.036 \\
JN (Private) & 0.953 & 0.040 \\
HS (5-7) & 1.942 & 0.029 \\
MI (2001-4000) & 1.789 & 0.013 \\
MI (4001-6000) & 2.777 & 0.005 \\
MI ( $>6000)$ & 2.984 & 0.002 \\
TO (M. Bike) & -1.744 & 0.002 \\
TO (Bike+Car) & -1.957 & 0.001 \\
Nagelkerke $R^{2}$ & 0.456 & \\
Chi-Square & 25.116 & \\
Log-likelihood & 25.116 & \\
df & 08 & \\
Hosmer \& Lemeshow & 0.001 &
\end{tabular}

There are five predictive variables, some of which are categorical and have different choices. From these variables, gender, postsecondary education level, private jobs, household size, which included five to seven members, income level, which included RM 2001-4000, RM 4001-6000, and above RM 6000, and the transportation ownership was found to be statistically significant, which is shown in Table 2 . The regression coefficient for gender was significant, $\beta=1.751, O R=5.760$, and $p<0.001$, which indicates that males 
had 5.76 times higher odds to exhibit a willingness to adopt the P\&RS than females. Similarly, the post-secondary educational level was significant, which included $\beta=0.937$ and $p<0.036$, and it revealed the odds of being 2.5 times higher towards the adoption of the $P \& R S$. The regression coefficient for the private job category was significant with $\beta=0.953$, $O R=2.593$, and $p=0.040$, which represents that a person with a private job's willingness to use the P\&RS would increase by approximately $159 \%$. In contrast, households with five to seven people were 6.97 times more likely to desire to use the P\&RS. Income between the RM 2000 level and the RM 4000 level, between the RM 4001 level and the RM 6000, and above the RM6000 level categories had 5.986 higher odds, which indicated that they were more liable to switch towards the P\&RS. Similarly, all the transportation ownership groups were significant and had a minimum decrease of $82 \%$ towards the willingness of cluster 1 . Therefore, it was observed that the gender, income, household, and ownership variables had a positive influence on the use of the P\&RS. In contrast, ownership of the transportation method had a negative influence, or the factors that influenced it did not express willingness towards P\&RS.

\subsection{Model 2}

The environment model is designated as Model 2. The BLR was conducted to examine whether IV, which included harsh weather $(H W)$, had a significant effect on the willingness to switch towards the P\&RS, which is shown in Table 4 . The reference category for the willingness to switch was 0, which is discussed above and in Equation (2).

$$
U_{\text {willingness to switch }}=\beta_{0}+\beta_{1} \times H W_{(\mathrm{No})}+\beta_{1} \times H W_{(\text {Neutral })}+\beta_{1} \times H W_{(Y e s)}
$$

Table 4. Logistic regression significant variables of Model 2.

\begin{tabular}{ccc}
\hline Environment Specific Factors & $\boldsymbol{\beta}$ & $\boldsymbol{p}$-Value \\
\hline$H W$ (Yes) & -3.131 & 0.001 \\
Nagelkerke $R^{2}$ & 0.677 & \\
Chi-Square & 0.109 & \\
Log-likelihood & 195.52 & \\
$d f$ & 03 & \\
Hosmer \& Lemeshow & 0.991 & \\
\hline
\end{tabular}

The overall model was statistically significant, $\chi^{2}(3)=0.109, p<0.001$, which suggests that the harsh weather has an important effect on the odds of observing one cluster of the willingness to switch. The McFadden $R^{2}$ value measured for this model was 0.677 . The classification table before, which includes the predictive variables, showed that $60 \%$ of the cases could be categorized if all the cases were categorized as the willingness to switch. However, after the inclusion of the independent variables, the model correctly classified $84.3 \%$ of the overall cases. The sensitivity was $91.7 \%$, specificity was $79.4 \%$, the model's positive predictive value was $93.46 \%$, and the negative predictive value was $74.82 \%$.

There is only one predictive variable, which is categorical and has different choices. The regression coefficient for harsh weather (Yes) was significant, $\beta=-3.131, \mathrm{OR}(\operatorname{Exp}(\beta))=37.308$, and $p<0.001$, which indicates that harsh weather had 37.3 times higher odds of influencing not to adopt the P\&RS. Therefore, it was proven that harsh weather has a significant impact on the private transportation users. Another way to put this is that in harsh weather, individual transportation users are not willing to switch towards the P\&RS.

\subsection{Model 3}

The trip model is designated as Model 3. It consists of dropping kids to school $(D K)$, dropping off family members $(D F)$, going shopping $(G S)$, effects of travel time $(E T T)$, trips per day $(T P D)$, travel time per trip (TTPT), traveling directly $(T D)$, travel expenses (TE), and the workplace distance (WD). The BLR was conducted to examine whether the IVs significantly affected the willingness to switch towards the P\&RS, which 
is shown in Equation (3). The reference group for the willingness to shift was 0, which is discussed above.

$$
\begin{aligned}
& U_{\text {willingness to switch }} \\
& =\beta_{0}+\beta_{1} \times D K_{(\mathrm{No})}+\beta_{1} \times D K_{(\text {Neutral })} \\
& +\beta_{1} \times D K_{(Y e s)}+\beta_{2} \times D F_{(N o)} \\
& +\beta_{2} \times D F_{(\text {Neutral })}+\beta_{2} \times D F_{(Y e s)} \\
& +\beta_{3} \times G S_{(\mathrm{No})}+\beta_{3} \times \mathrm{GS}{ }_{(\mathrm{Neutral})} \\
& +\beta_{3} \times G S_{\left(Y_{e s}\right)}+\beta_{4} \times E T T_{(\mathrm{No})} \\
& +\beta_{4} \times \operatorname{ETT}_{(\text {Neutral })}+\beta_{4} \times \operatorname{ETT}_{(\mathrm{Yes})} \\
& +\beta_{5} \times T P D_{1}+\beta_{5} \times T P D_{2}+\beta_{5} \times T P D_{3} \\
& +\beta_{6} \times \operatorname{TTPT}_{(5-10 \text { mins })}+\beta_{6} \times \mathrm{TTPT}_{(11-20 \text { mins })} \\
& +\beta_{6} \times \operatorname{TTPT}_{(21-30 \text { mins })}+\beta_{6} \times \operatorname{TTPT}_{(30 \text { mins })} \\
& +\beta_{7} \times T D_{(Y e s)}+\beta_{7} \times T D_{N o}+\beta_{8} \times T E_{(<R M 100)} \\
& +\beta_{8} \times T E_{(R M 100-300)}+\beta_{8} \times T E_{(R M 301-600)} \\
& +\beta_{8} \times T E_{(>R M 600)}+\beta_{9} \times W D_{(<10 \mathrm{~km})} \\
& +\beta_{9} \times W D_{(10-15 k m)}+\beta_{9} \times W D_{(15-20 k m)} \\
& +\beta_{9} \times W D_{(<20 \mathrm{~km})}
\end{aligned}
$$

The overall model was statistically significant, $\chi^{2}(8)=14.504$ and $p<0.001$, which suggests that dropping off kids, dropping off family members, traveling time, trips per day, travel time per trip, travel expenses, travel directly from home to the office and the office to home, and distance from home to the workplace significantly affected the odds of observing 1 category of the willingness to switch. The McFadden R-squared computed for this model was 0.785 . The classification table before, which includes the predictive variables, showed that $60 \%$ of the cases could be appropriately categorized if all the cases were categorized as the willingness to switch. However, after the inclusion of the independent variables, the model correctly classified $92.3 \%$ of the overall cases. The sensitivity was $90.8 \%$, specificity was $93.3 \%$, the model's positive estimated value was $93.85 \%$, and the negative estimated value was $90.08 \%$.

There were nine predictive variables, of which eight were categorical and had different choices. Among the variables, dropping off kids (No), dropping family member (No), effects of travel time (No), trips per day (1), travel time per trip, which includes 11-20 min and above $30 \mathrm{~min}$, traveling directly (Yes), and travel expenses (RM 301-600) were found to be positively statistically significant, which is shown in Table 5. The individual travelers who do not drop off their children or family members have more influence to use or to adopt the P\&RS than the travelers who drop off their children or family members. Similarly, effects of travel time (No) means the effect of travel time variable has no influence on the travelers, and it is positively significant, $\beta=2.449$ and $p=0.002$, to adopt the P\&RS. The regression coefficient for travel times between 11-20 min was significant, $\beta=2.729$, $O R=15.315$, and $p<0.006$, which indicates that the travel time had influenced the odds 15.3 times higher to exhibit a willingness to adopt the P\&RS. Similarly, travel time above 30 min was significant at $\beta=4.534$ and $O R=17.81$, which shows that it has 17 times more odds towards adopting the P\&RS. Consequently, travel expenses of RM 301-600 was found significant at $\beta=2.880$ with an odds ratio that is 17.81 times greater to switch towards the P\&RS. Furthermore, there was only workplace distance that had a negative influence. Workplace distances $10-15 \mathrm{~km}$ with $\beta=-3.440$ and $p<0.000$, which reflected $31 \%$ odds towards not willing to use the P\&RS. Similarly, distance $15-20 \mathrm{~km}$ with $\beta=-3.349$ and a $p$-value of 0.028 had odds of almost $31 \%$ regarding unwillingness to adopt the P\&RS, which is shown in Table 4. Additionally, it seems that the travelers with a distance of 10-15 and 15-20 km between home and the office are not willing to use the P\&RS. 
Table 5. Variance inflation factors for model 3.

\begin{tabular}{ccc}
\hline Trip Specific Factors & $\beta$ & $p$-Value \\
\hline$D K($ Neutral $)$ & 2.994 & 0.005 \\
$D K($ No) & 4.092 & 0.030 \\
$D F($ Neutral) & 3.535 & 0.008 \\
ETT (No) & 2.449 & 0.002 \\
$T P D(1)$ & 2.351 & 0.056 \\
$T T$ 11-20 min & 2.729 & 0.006 \\
$T T$ above 30 min & 4.534 & 0.005 \\
$T D($ Yes $)$ & 1.464 & 0.028 \\
TE RM301-600 & 2.880 & 0.025 \\
WD 10-15 Km & -3.440 & 0.000 \\
WD 15-20 Km & -3.439 & 0.028 \\
Nagelkerke $R^{2}$ & 0.785 & \\
Chi-Square & 14.504 & \\
Log-likelihood & 142.853 & \\
$d f$ & 8 & \\
Hosmer \& Lemeshow & 0.070 & \\
\hline
\end{tabular}

Therefore, the results show that SOV users with a workplace distance (WD) of $10-20 \mathrm{~km}$ are not willing to adopt the P\&R service. Nevertheless, the other result shows that SOV users with travel time (TT) of 11-20 min are willing to adopt the P\&R service. Hence, it clarified that traffic jams during peak times at the fringes of Putrajaya discourage short distance travelers from the usage of their vehicle.

\subsection{Model 4}

The transport model, which includes mode of travelling $(M T)$, the frequency of bus $(F B)$, and an improper location for a P\&RS (ILP\&R), are designated as Model 4. The BLR was conducted to examine whether the IVs significantly affected the odds of observing a category coded as one of the willingness to switch towards the P\&RS, which is shown in Equation (4).

$$
\begin{aligned}
& U_{\text {willingness to switch }} \\
& =\beta_{0}+\beta_{1} \times M T_{(\text {Bike })}+\beta_{1} \times M T_{(\text {Car })} \\
& +\beta_{2} \times F B_{(5 \text { mins })}+\beta_{2} \times F B_{(10 \text { mins })} \\
& +\beta_{2} \times F B_{(15 \text { mins })}+\beta_{2} \times F B_{(20 \text { mins })} \\
& +\beta_{3} \times I L P \& R_{(N o)}+\beta_{3} \times I L P \& R_{(\text {Neutral })} \\
& +\beta_{3} \times I L P \& R_{(Y e s)}
\end{aligned}
$$

The overall model was statistically significant, $\chi^{2}(7)=11.48$ and $p<0.001$, which suggests that the mode of travelling, frequency of buses, and an improper location for a P\&RS significantly affected the odds of observing one category of the willingness to switch. The McFadden R-squared value measured for this model was 0.305 . The previous classification table, which included the predictive variables, showed that $60 \%$ of the cases could be accurately categorized if all the cases were categorized as the willingness to switch. However, after the inclusion of the independent variables, the model correctly classified $74 \%$ of the overall cases. The sensitivity was $94.4 \%$, specificity was $43.3 \%$, the model's positive estimated value was $71.42 \%$, and the negative estimated value was $83.87 \%$.

There were three predictive variables, and all of these variables were categorical and had different choices. Among these variables, the mode of travelling (bike) and the frequency of buses $(15 \mathrm{~min}$ ) were found to be positively significant, which is shown in Table 6. The bike as a mode of travelling was found to be significant with $\beta=0.847$ and a $p$-value equal to 0.006 , which predicts adopting the P\&RS with an odds ratio of 2.334 . The regression coefficient for the frequency of buses $(15 \mathrm{~min})$ was significant with $\beta=1.063$ and $O R=2.896$, which indicates that the frequency of buses every $15 \mathrm{~min}$ attracts the travelers 
towards the P\&RS. In contrast, the improper location of a P\&RS location (Yes) is negatively significant at $\beta=-2.591$ and has 0.075 higher odds, which shows that a location of a P\&R has a significant impact on the adoption of the P\&RS. The improper location of P\&R service clarifies that the location of P\&R station is not on an appropriate route for the SOV users. It shows that the P\&R station must be on the most appropriate route which should be convenient for SOV users.

Table 6. Logistic regression significant variables of Model 4.

\begin{tabular}{ccc}
\hline Transport Specific Factors & $\boldsymbol{\beta}$ & $\boldsymbol{p}$-Value \\
\hline MT (Bike) & 0.847 & 0.006 \\
$F B(15$ min $)$ & 1.063 & 0.003 \\
$I L P \& R($ Yes $)$ & -2.591 & 0.000 \\
Nagelkerke $R^{2}$ & 0.305 & \\
Chi-Square & 11.48 & \\
Log-likelihood & 327.1 & \\
$d f$ & 7 & \\
Hosmer \& Lemeshow & 0.119 & \\
\hline
\end{tabular}

\subsection{Model 5}

The quality model is designated as Model 5, which consists of the IVs that include the comfort preference $(C P)$ and expensive parking at the workplace $(E P W)$. The BLR was conducted to examine whether the IVs had a significant effect on the willingness to switch towards the P\&RS, which is shown in Equation (5).

$$
\begin{aligned}
& U_{\text {willingness to switch }} \\
& =\beta_{0}+\beta_{1} \times C P \text { (Seat availability or easy standing) } \\
& +\beta_{1} \times C P(\text { Seat availability) } \\
& +\beta_{2} \times E P W_{(\text {remain with current mode of transport })} \\
& \left.+\beta_{2} \times E P W_{(\text {Safe }} \text { and secure } P \& R \text { with nominal cost }\right) \\
& +\beta_{2} \times E P W_{(\text {Safe }} \text { and Secure P\&R without any cost) }
\end{aligned}
$$

The overall model was statistically significant, $\chi^{2}(7)=8.298$ and $p<0.001$, which suggests that the comfort preference, which includes an air-conditioned bus with seat availability or easy standing, and expensive parking at the workplace, which includes safe and secure P\&RS with a nominal cost, significantly affected the odds of observing one category of the willingness to switch. The McFadden R-squared value measured for this model was 0.603 . The classification table before, which includes the predictive variables, disclosed that $60 \%$ of the cases could be accurately categorized simply if all the cases were categorized as the willingness to switch. However, after the inclusion of the independent variables, the model correctly classified $80 \%$ of the overall cases. The sensitivity was $72.5 \%$, specificity was $85 \%$, the model's positive estimated value was $82.25 \%$, and the negative estimated value was $76.31 \%$.

There were two predictive variables, and both of these variables were categorical and had different choices. Among these variables, avoiding mental stress (Yes), the comfort preference, which includes an air-conditioned bus with seat availability or easy standing, and expensive parking at the workplace, which includes safe and secure P\&RS with a nominal cost, were found to be positively significant, which are shown in Table 7. 
Table 7. Logistic regression significant variables of Model 5.

\begin{tabular}{ccc}
\hline Quality Specific Factors & $\boldsymbol{\beta}$ & $\boldsymbol{p}$-Value \\
\hline$C P($ AC bus with seat availability or easy standing) & 1.416 & 0.00 \\
$E P W$ (Safe \& secure P\&RS with nominal cost) & 1.374 & 0.04 \\
Constant & -2.542 & 0.000 \\
Nagelkerke $R^{2}$ & 0.603 & \\
Chi-Square & 8.298 & \\
Log-likelihood & 226.5 & \\
$d f$ & 7 & \\
Hosmer \& Lemeshow & 0.307 & \\
\hline
\end{tabular}

The regression coefficients of the comfort preferences option, an air-conditioned bus with seat availability or easy standing, are positively significant $\beta=1.416$ with a $p$-value of 0.00 , and it has 4.1 times higher odds of adopting the P\&RS. Similarly, expensive parking at the workplace would encourage private transportation for the safe and secure P\&RS at a nominal cost, which has 3.95 times higher odds, a $\beta=1.374$, and a $p=0.04$. It predicts that the comfort preference, which includes an air-conditioned bus with the availability of a seat or easy standing, and expensive parking at the workplace, which includes safe and secure P\&RS with a nominal cost, have a significant influence on willingness to switch towards the P\&RS.

\subsection{Model 6}

Model 6 illustrates the attitude model, which has the IVs that include the personal status $(P S)$, privacy, and the car is convenient $(C C)$. The BLR was conducted to examine whether the IV's significantly affected the odds of observing the cluster coded as one of the willingness to switch towards the P\&RS, which is shown in Equation (6).

$$
\begin{aligned}
& U_{\text {willingness to switch }} \\
& =\beta_{0}+\beta_{1} \times P S_{(\mathrm{No})}+\beta_{1} \times P S_{(\text {Neutral })} \\
& +\beta_{1} \times P S_{(Y e s)}+\beta_{2} \times \text { Privacy }_{(\mathrm{No})} \\
& +\beta_{2} \times \text { Privacy }_{(\text {Neutral })}+\beta_{2} \times \text { Privacy }_{\left(Y_{e s}\right)} \\
& +\beta_{3} \times C C_{(\mathrm{No})}+\beta_{3} \times \mathrm{CC}_{(\text {Neutral })}+\beta_{3} \times \mathrm{CC}_{(\mathrm{Yes})}
\end{aligned}
$$

The overall model was statistically significant, $\chi^{2}(2)=88.521$ and $p<0.001$, which suggests that the personal status (Yes), privacy (Yes), and cars are convenient (Yes) are significantly affected by the odds of observing one category of the willingness to switch. The McFadden $R$-squared value measured for this model was 0.596 . The previous classification table, which includes the predictive variables, showed that $60 \%$ of the cases could be accurately categorized if all the cases were categorized as the willingness to switch. However, after the inclusion of the independent variables, the model correctly classified $88.3 \%$ of the overall cases. The sensitivity was $76.7 \%$, specificity was $96.7 \%$, the model's positive estimated value was $86.06 \%$, and the negative estimated value was $92.92 \%$.

There were three predictive variables, which were all categorical, and had different choices. All the variables, which included the personal status (Yes), privacy (Yes), and cars are convenient (Yes) were found to be negatively significant as shown in Table 8, which predicts that all these variables have an influence on the SOV users to stick with their current mode of transportation instead of switching to the P\&RS. The convenience of the car is also a strong factor, which motivates SOV users to stick with their current mode of transport. 
Table 8. Logistic regression significant variables of Model 6.

\begin{tabular}{ccc}
\hline Attitude Specific Factors & $\beta$ & $p$-Value \\
\hline PS (Yes) & -2.6 & 0.000 \\
Privacy (Yes) & -2.1 & 0.000 \\
CC (Yes) & -1.5 & 0.005 \\
Constant & 1.73 & 0.000 \\
Nagelkerke $R^{2}$ & 0.59 & \\
Chi-Square & 88.851 & \\
Log-likelihood & 229.3 & \\
$d f$ & 02 & \\
Hosmer \& Lemeshow & 0.00 & \\
\hline
\end{tabular}

\subsection{Model 7}

Model 7 illustrates the uncertainty model. It consists of the IVs, which include safety and security at $P \& R(S S P \& R)$, the threat of robbery and snatching $(T R S)$, and the threat of terrorism/violence (TTV). The BLR was conducted to examine whether the IVs significantly affected the odds of observing cluster coded as one of the willingness to switch towards the P\&RS, which is shown in Equation (7).

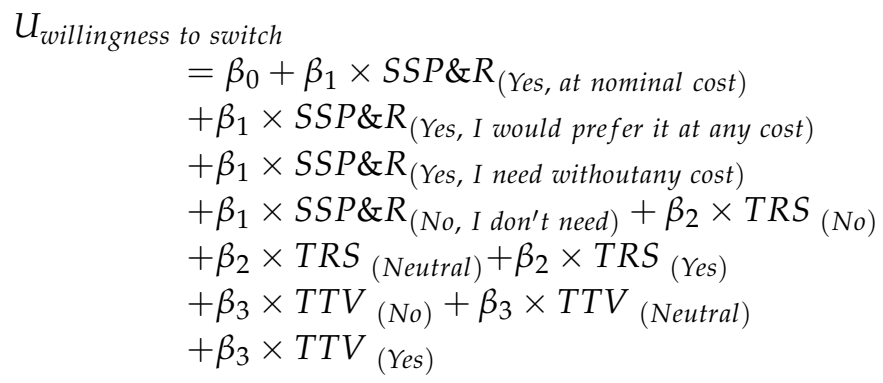

The overall model was statistically significant, $\chi^{2}(6)=32.73$ and $p<0.001$, which suggests that safety and security at $P \& R$, the threat of robberies and having items snatched, and the threat of terrorism, significantly affected the odds of observing one category of the willingness to switch. The McFadden R-squared value measured for this model was 0.409 . The previous classification table, which includes the predictive variables, showed that $60 \%$ of the cases could be accurately categorized if all the cases were categorized as a willingness to switch. However, after the inclusion of the independent variables, the model correctly classified $75.7 \%$ of the overall cases. The sensitivity was $50 \%$, specificity was $92.8 \%$, the model's positive estimated value was $73.56 \%$, and the negative estimated value was $82.19 \%$.

There were three predictive variables, and all of these variables were categorical and had different choices. Among these variables, only the safety and security of the P\&RS (Yes, I would prefer it at any cost) were found to be positively significant, which is shown in Table 9. This reflects that the travelers are willing to adopt the P\&RS with a high $\beta=1.465$, and there are 4.28 times greater odds with safety and security at any cost. Furthermore, the threat of having items snatched and robberies (Yes) and the threat of terrorism (Yes) were negatively significant towards the adoption of the P\&RS. This reflects that the threat of terrorism, robberies, the threat of having items snatched, and violence influence the private transport users, which affect them using the P\&RS. 
Table 9. Logistic regression significant variables of Model 7.

\begin{tabular}{ccc}
\hline Safety and Security Specific Factors & $\boldsymbol{\beta}$ & $\boldsymbol{p}$-Value \\
\hline SSP\&R (Yes, I would prefer it at any cost) & 1.465 & 0.020 \\
TRS (Yes) & -2.091 & 0.003 \\
TTV (Yes) & -1.892 & 0.002 \\
Nagelkerke $R^{2}$ & 0.409 & \\
Chi-Square & 32.73 & \\
Log-likelihood & 295.6 & \\
$d f$ & 6 & \\
Hosmer \& Lemeshow & 0.00 & \\
\hline
\end{tabular}

In conclusion, the variables, which were positively and negatively significant in Model 1 to Model 7 of Putrajaya, are presented in Figure 4. The sociodemographic factors, which include ownership of a bike and bike + car, are negative. Additionally, gender, educational level, job nature, household size, and income were positive significant variables. Similarly, with the environment-specific factors, harsh weather is also a reason to discourage the private transportation users to use the P\&RS. With the trip-specific factors, distance from home to the office between 10-15 km and 15-20 km were negative, dropping off children, dropping off family members, travel time, and trips per day are positive influential variables. Correspondingly, in the transport-specific factors, the improper location of a P\&RS (Yes) was negative, and a bike as a mode of travelling and the frequency of a bus every 15 min were a positive influence with the adoption of the P\&RS, which is shown in Figure 4.

The quality-specific factors, which include the comfort preference and expensive parking at the workplace, are positively significant. In contrast, attitude-specific factors, which include personal status, privacy, and cars, are convenient and have a negative influence on the adoption of the P\&RS. Uncertainty-specific factors, which include having items stolen and robberies and the threat of terrorism and violence factors have a negative impact towards the use of the P\&RS. Therefore, Figure 4 is a complete framework of the factors that positively and negatively influence the private transport users. We can understand the different attributes and the different measures that influence the adaptability of the P\&RS through this figure. 


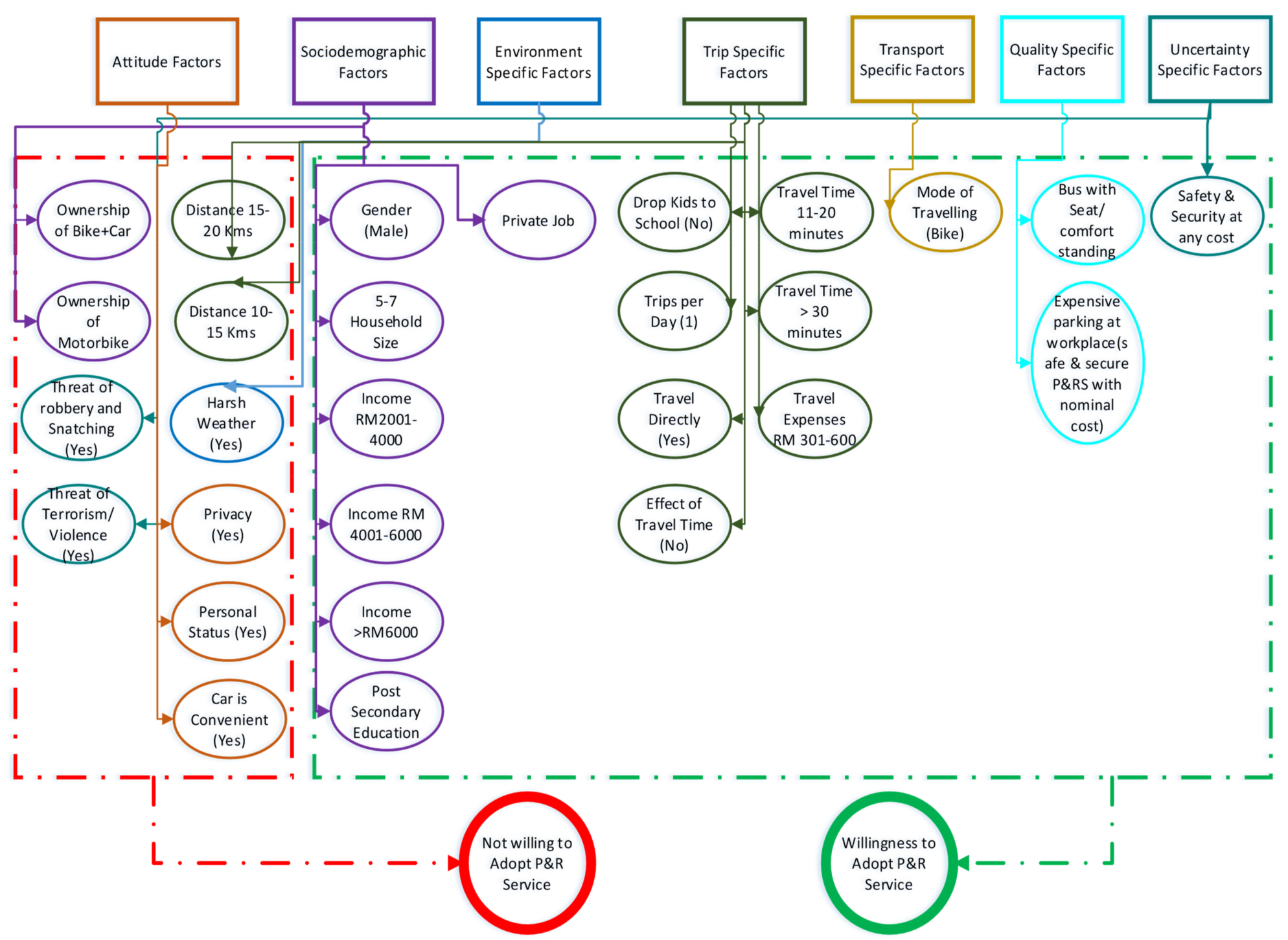

Figure 4. Putrajaya's significant factors to shift and not to shift towards P\&R services. 


\subsection{Model 8}

Model 8 illustrates the final model. In this model, all of the IVs, which were significant in Model 1 to Model 7, are included. The BLR was conducted to examine the independent variables from Model 1 to Model 7, which were significantly affected by the odds of observing the cluster of the willingness to switch towards the P\&RS. Therefore, the fit variables into the model included the gender, educational level $(E L)$, job nature $(J N)$, household size $(H S)$, monthly income $(M I)$, trips per day (TPD), travel time per trip (TTPT), travel directly $(T D)$, travel expenses $(T E)$, comfort preferences $(C P)$, harsh weather $(H W)$, dropping off kids $(D K)$, dropping off family members $(D F)$, and personal status (PS), which are shown in Equation (8).

$$
\begin{aligned}
& U_{\text {willingness to switch }} \\
& =\beta_{0}+\beta_{1} \times \text { Gender }_{\text {Female }}+\beta_{1} \times \text { Gender }_{\text {Male }} \\
& +\beta_{2} \times E L_{\text {Secondary }}+\beta_{2} \times E L_{\text {Post.Secondary }} \\
& +\beta_{2} \times E L_{\text {Post-Graduation }}+\beta_{2} \times E L_{P h D} \\
& +\beta_{3} \times J N_{(\text {Govt: })}+\beta_{3} \times J N_{(\text {Private })} \\
& +\beta_{3} \times J N_{(\text {Banking })}+\beta_{4} \times H S_{1}+\beta_{4} \times H S_{2-4} \\
& +\beta_{4} \times H S_{5-7}+\beta_{4} \times H S_{>7}+\beta_{5} \times M I_{<R M 1000} \\
& +\beta_{5} \times M I_{<R M 1000-2000}+\beta_{5} \times M I_{R M 2001-4000} \\
& +\beta_{5} \times M I_{R M 4001-6000}+\beta_{5} \times M I_{>R M 6000} \\
& +\beta_{6} \times D F_{(\mathrm{No})}+\beta_{6} \times D F_{(\text {Neutral })} \\
& +\beta_{6} \times D F_{(Y e s)}+\beta_{7} \times \text { Trips per Day } 1 \\
& +\beta_{7} \times \text { Trips per Day } 2+\beta_{7} \times T P D_{3} \\
& +\beta_{8} \times \operatorname{TTPT}_{(5-10 \mathrm{mins})}+\beta_{8} \times \mathrm{TTPT}_{(11-20 \mathrm{mins})} \\
& +\beta_{8} \times \operatorname{TTPT}_{(21-30 \mathrm{mins})}+\beta_{8} \times \operatorname{TTPT}_{(30 \mathrm{mins})} \\
& +\beta_{9} \times T D_{(Y e s)}+\beta_{9} \times T D_{N o}+\beta_{10} \times T E_{(<R M 100)} \\
& +\beta_{10} \times T E_{(R M 100-300)}+\beta_{10} \times T E_{(R M 301-600)} \\
& +\beta_{10} \times T E_{(>R M 600)} \\
& +\beta_{11} \times C P \text { (Seat availability or easy standing) } \\
& +\beta_{11} \times C P \text { (Seat availability) }+\beta_{12} \times H W_{(\mathrm{No})} \\
& +\beta_{12} \times H W_{(\text {Neutral })}+\beta_{12} \times H W_{\left(Y_{\text {es }}\right)} \\
& +\beta_{13} \times P S_{(\mathrm{No})}+\beta_{13} \times P S_{(\text {Neutral })} \\
& +\beta_{13} \times P S_{(Y e s)}
\end{aligned}
$$

The overall model was statistically significant, $\chi^{2}(8)=6.597$ and $p<0.001$, which suggests that the educational level, job nature, income, trips per day, travel time per trip, travel directly, and personal status significantly affected the odds of observing the cluster of the willingness to switch. The McFadden R-squared value measured for this model was 0.875 . The previous classification table, which includes the predictive variables, reflects that $60 \%$ of the cases could be accurately categorized simply if all the cases were categorized as the willingness to switch. However, after the inclusion of the independent variables, the model correctly classified $94 \%$ of the overall cases. The sensitivity was $91.7 \%$. The model's positive estimated value was $94.50 \%$, and the negative estimated value was $93.22 \%$, which is described in Table 10.

There were nineteen significant variables from Model 1 to Model 7, and all of these variables were categorical and had different choices. From these variables, the educational level (post-secondary), job nature (government and private job), monthly income (RM 2001-4000 and RM 4001-6000), and travel time per trip (11-20 and above $30 \mathrm{~min}$ ) were found to be positively significant, which are shown in Table 9 and Figure 5.

There were nineteen significant variables from Model 1 to Model 7, and all of these variables were categorical and had different choices. From these variables, the educational level (post-secondary), job nature (government and private job), monthly income (RM 2001-4000 and RM 4001-6000), and travel time per trip (11-20 and above $30 \mathrm{~min}$ ) were found to be positively significant, which are shown in Table 9 and Figure 5. Similarly, 
trips per day (two and three) and traveling directly (no) were predicted to be negatively significant, which reflects that sharing a vehicle, do not travel directly, and more than one trip per day from home to the office discourage the SOV users to shift towards the P\&RS.

Table 10. Logistic regression significant variables of the final model.

\begin{tabular}{ccc}
\hline Final Model's Variables & $\boldsymbol{\beta}$ & $p$-Value \\
\hline$E L$ (Post-Secondary) & 4.04 & 0.018 \\
$J N$ (Government Job) & 4.27 & 0.009 \\
$J N$ (Private Job) & 7.14 & 0.001 \\
$M I(2001-4000)$ & 6.33 & 0.027 \\
$M I(4001-6000)$ & 12.6 & 0.001 \\
$T P D(2)$ & -7.25 & 0.000 \\
$T P D(3)$ & -9.01 & 0.001 \\
$T T P T(11-20$ min) & 5.12 & 0.003 \\
$T T P T$ (30 min \& Above) & 6.28 & 0.000 \\
$T D($ No) & -5.61 & 0.000 \\
$P S($ Yes) & -8.10 & 0.002 \\
Constant & 1.14 & 0.771 \\
Nagelkerke $R^{2}$ & 0.875 & \\
Chi-Square & 6.597 & \\
Log-likelihood & 91.39 & \\
$D f$ & 8 & \\
Hosmer \& Lemeshow & 0.581 & \\
\hline
\end{tabular}

Therefore, it is concluded that graduates who have an income between RM 20014000 and RM 4001-6000, travel directly, and have a trip time that is $11 \mathrm{~min}$ to $20 \mathrm{~min}$ or more than $30 \mathrm{~min}$ are willing to adopt the P\&RS. The logistic regression path analysis for the final model of Putrajaya is presented with the significant variables and their $\beta$ values in Figure 5 below.

\subsection{Validation of Models}

Validation of Final Models was done through training and testing through a logistic regression approach. All the variables which were significant in Model; 1, 2, 3, 4, 5, 6 and 7, were selected for Model 8 of Putrajaya. Additionally, variables that were fitted in Model 8 were included in the report. Similarly, Model 8 (Final Model) was selected for validation.

\subsection{Training and Testing Approach for Final Model of Putrajaya}

The validation of the model is performed through training and testing samples through a binary logistic regression approach. There were 133 samples were selected for training, and 167 samples from 300 were taken for testing purposes. The further details and classification table of model validation are presented in Table 11.

Table 11. Classification Table of Significant variables of Final Model at 0.05.

\begin{tabular}{|c|c|c|c|c|c|c|c|}
\hline \multirow{4}{*}{ Observed } & & \multicolumn{6}{|c|}{ Predicted } \\
\hline & & \multicolumn{3}{|c|}{ Training Sample } & \multicolumn{3}{|c|}{ Testing Sample } \\
\hline & & \multicolumn{2}{|c|}{$\begin{array}{l}\text { Response Recorded } \\
(1=\text { Yes, } 0=\text { No })\end{array}$} & \multirow{2}{*}{ Percentage Correct } & \multicolumn{2}{|c|}{$\begin{array}{l}\text { Response Recorded } \\
(1=\text { Yes, } 0=\text { No })\end{array}$} & \multirow{2}{*}{ Percentage Correct } \\
\hline & & No & Yes & & No & Yes & \\
\hline $\begin{array}{l}\text { Response recorded } \\
(1=\text { Yes, } 0=\mathrm{No})\end{array}$ & $\begin{array}{l}\text { No } \\
\text { Yes }\end{array}$ & $\begin{array}{c}53 \\
0\end{array}$ & $\begin{array}{c}0 \\
80\end{array}$ & $\begin{array}{l}100.00 \\
100.00\end{array}$ & $\begin{array}{l}63 \\
11\end{array}$ & $\begin{array}{c}4 \\
86\end{array}$ & $\begin{array}{l}94.03 \\
89.00\end{array}$ \\
\hline \multicolumn{2}{|c|}{ Overall Percentage } & 0.00 & 100.00 & 100.00 & 14.86 & 95.70 & 91.02 \\
\hline
\end{tabular}




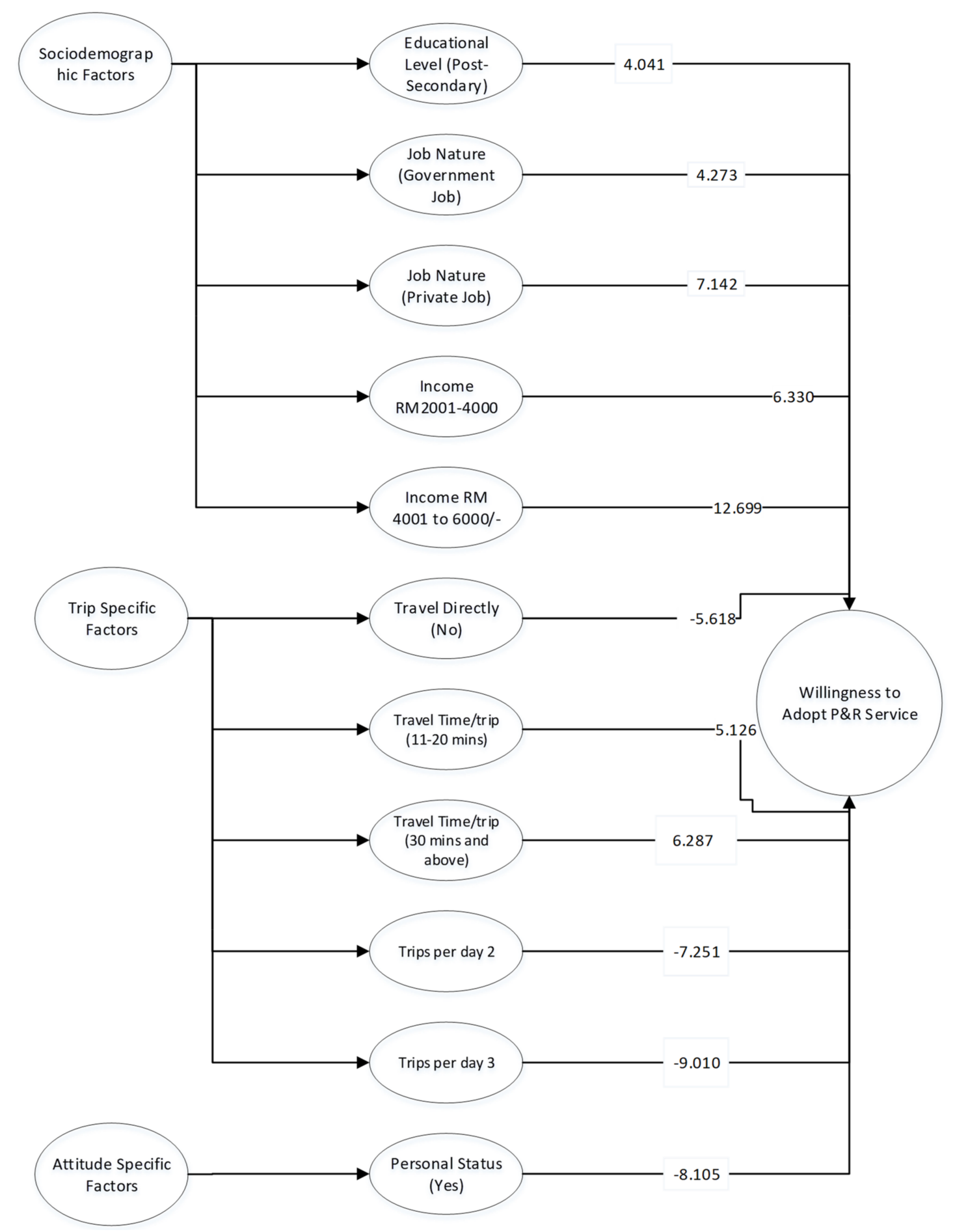

Figure 5. Final model's path analysis of logistic regression for Putrajaya.

Training Sample: For those predicted to have a positive response, the correct classification rate for actual positive responses is $100.00 \%$.

Testing Sample: For those predicted to have a positive response, the correct classification rate for actual positive responses is $95.70 \%$.

This is greater than or equal to the specified minimum probability of 0.050 or $5.00 \%$. This suggests that this model could be used to identify a set of contacts that would meet or exceed the specified minimum probability value. Note, however, that the correct classification rate for the actual positive responses for the testing sample is lower than the correct rate for the training sample. This is not unusual, but if there is a large difference, 
caution should be used when interpreting these results. The overall Model quality of the Final Model of Putrajaya is shown in Figure 6.

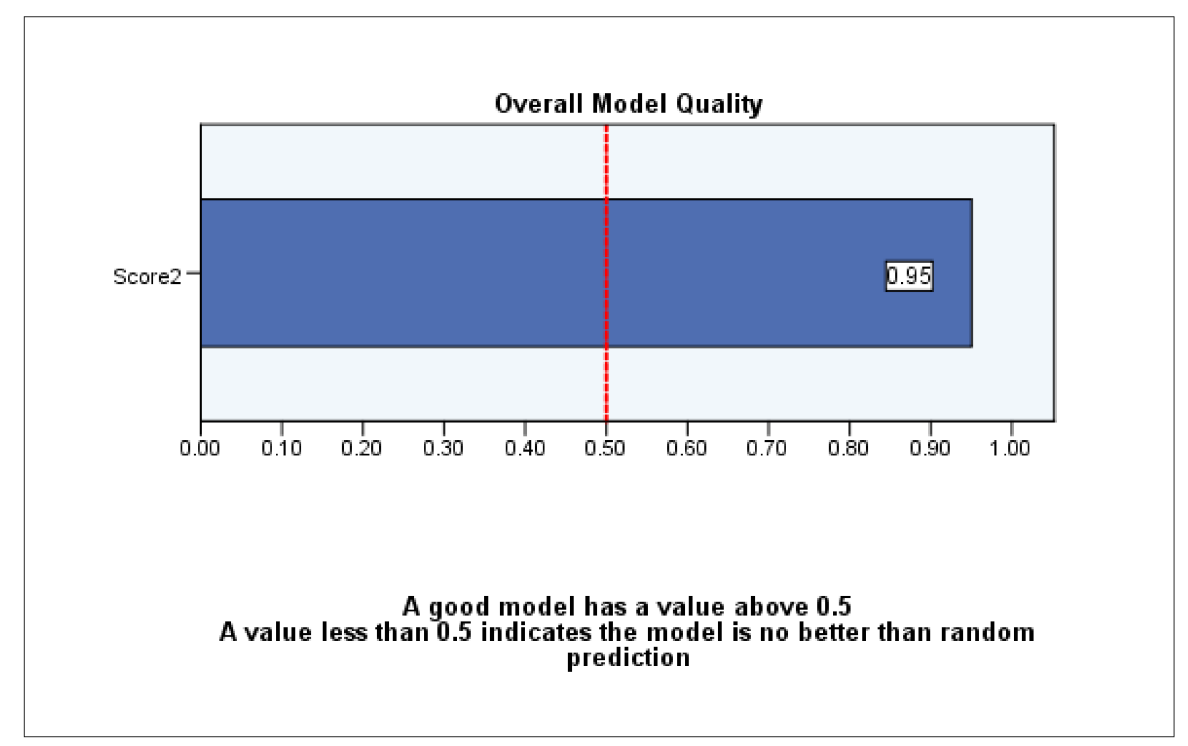

Figure 6. Overall Model Quality of Final Model of Putrajaya.

\section{Conclusions}

The Putrajaya city center was tested for the willingness to adopt sustainable alternative mode choice the P\&RS. It was concluded from the study that many factors have positive and negative influences on the mode choice of the travelers. Private transportation users are willing to use the P\&RS because it is the most sustainable and successful approach under certain conditions. There were seven major factors, which included thirty-seven variables. In this study, binomial logistic modelling was applied. In conclusion, Putrajaya's final model had eleven significant variables, which included the educational level (postsecondary), monthly income (RM 2000-4000 and RM 4001-6000), job nature (government and private), trips per day (two and three), travel time per trip (11-30 min and above $30 \mathrm{~min}$ ), travel directly (No), and personal status (Yes). It can be assumed that the middleincome group and the upper-income group, which especially included from the RM 2000 income level to the RM 6000 income level, a travel time from $11 \mathrm{~min}$ to $20 \mathrm{~min}$ and above $30 \mathrm{~min}$ and travel directly from home to the office are willing to adopt the P\&RS. The influencing factors that are discussed above indicate that the personal status and trip distribution, such as do not travel directly from home to the office, are also a major concern for the private car users, but the safety and security factors did not fit into the final model of Putrajaya.

Therefore, the results show that SOV users with a workplace distance (WD) of 10-20 km are not willing to adopt the P\&R service. Nevertheless, the other result shows that SOV users with travel time (TT) of 11-20 min are willing to adopt the P\&R service. Hence, it clarified that traffic jams during peak times at the fringes of Putrajaya discourage short distanced travellers from the usage of their vehicle. Fifty percent of all the users of the P\&RS had distances of more than $20 \mathrm{~km}$ from their homes to their offices. It was also observed that the majority of the P\&RS users were directly traveling from their homes to their offices, which took above 20 min to more than 30 min per trip. Traffic congestion, the fare rate being cheaper than the SOV, parking problems at the workplace, and safety and security at the P\&RS lot were the major concerns. It was also interesting to know that almost $40 \%$ of the users adopted the P\&RS to avoid mental stress. The improper location of the $P \& R$ service clarifies that the location of the $P \& R$ station is not on an appropriate route for the SOV users. It shows that the P\&R station must be on the most appropriate route which should be convenient for SOV users. Therefore, this study attempted to give 
a holistic mode choice model with almost all of the possible influencing factors, which include influencing the SOV users. Consequently, all the significant factors of the models were gathered into one model. However, the fitted variables produced the essence of swift influencing factors, which is known as the Model 8 (Final Model) of Putrajaya.

Author Contributions: A Conceptualization, I.A.M., M.N. and M.Z.S.; methodology, I.A.M.; software, I.A.M., M.N.; validation, S.K., M.N.; formal analysis, I.A.M., N.S., S.K.; investigation, I.A.M.; resources, I.A.M.; data curation, I.A.M.; writing-original draft preparation, I.A.M.; writing-review and editing, I.A.M., M.N., J.H.; visualization, I.A.M., J.H., M.N., S.K.; supervision, M.N., M.Z.S.; project administration, M.N.; funding acquisition, J.H. All authors have read and agreed to the published version of the manuscript.

Funding: This research received no external funding.

Institutional Review Board Statement: Not Applicable.

Informed Consent Statement: Not Applicable.

Data Availability Statement: The data that support the findings of this study are available from the corresponding author upon reasonable request.

Conflicts of Interest: The authors declare no conflict of interest.

\section{References}

1. Memon, I.A. Mode Choice Modelling to Shift Car Travelers towards Park and Ride Service in the CBD of Putrajaya and Karachi. Ph.D. Thesis, Department of Civil and Environmental Engineering, Universiti Teknologi PETRONAS, 2018. Available online: http:/ / utpedia.utp.edu.my/id/eprint/18372 (accessed on 10 December 2020).

2. Peñalosa, E. Why buses represent democracy in action. In TEDCity2.0 Dream Me. Build Me. Make Me Real; Times Center: Manhattan, NY, USA, 2013; 20 September 2013; Available online: https:/ /www.ted.com/talks/enrique_penalosa_why_buses_ represent_democracy_in_action?language=en\#t-9156 (accessed on 12 December 2020).

3. InterestingEngineering. Can Traffic James Truly Be Avoided. Engineers Are Working Hard to Reduce Traffic Jams, But What Causes It in the First Place? Instagram, Ed. ; Loukia Papadopoulos: Toronto, ON, Canada, 2021.

4. Steg, L. Car use: Lust and must. Instrumental, symbolic and affective motives for car use. Transp. Res. Part A Policy Pract. 2005, 39, 147-162. [CrossRef]

5. Memon, I.A.; Napiah, M.; Talpur, M.A.H.; Hakro, M.R. Mode choice modelling method to shift car travelers towards Park and Ride service. ARPN J. Eng. Appl. Sci. 2016, 11, 3677-3683.

6. Hiscock, R.; Macintyre, S.; Kearns, A.; Ellaway, A. Means of transport and ontological security: Do cars provide psycho-social benefits to their users? Transp. Res. Part D Transp. Environ. 2002, 7, 119-135. [CrossRef]

7. Handy, S.; Weston, L.; Mokhtarian, P.L. Driving by choice or necessity? Transp. Res. Part A Policy Pract. 2005, 39, 183-203. [CrossRef]

8. Gärling, T.; Schuitema, G. Travel Demand Management Targeting Reduced Private Car Use: Effectiveness, Public Acceptability and Political Feasibility. J. Soc. Issues 2007, 63, 139-153. [CrossRef]

9. Memon, I.; Kalwar, S.; Sahito, N.; Talpur, M.; Chandio, I.; Napiah, M.; Tayyeb, H. Mode Choice Modeling to Shift Car Travelers towards Park and Ride Service in the City Centre of Karachi. Sustainability 2021, 13, 5638. [CrossRef]

10. Ahmed, Q.I.; Lu, H.; Ye, S. Urban transportation and equity: A case study of Beijing and Karachi. Transp. Res. Part A Policy Pract. 2008, 42, 125-139. [CrossRef]

11. Lawati, A. Why Expanding Roads Will Not Ease Traffic in Karachi. The Express Tribune. Available online: https://tribune.com. pk/story/1351571/expanding-roads-will-not-ease-traffic-karachi/ (accessed on 3 October 2017).

12. Knowles, R.D. What future for light rail in the UK after Ten Year Transport Plan targets are scrapped? Transp. Policy 2007, 14, 81-93. [CrossRef]

13. Victoria Transport Policy Institute. Park E Ride Convenient Parking for Transit Users; Online TDM Encyclopedia; Victoria Transport Policy Institute: Victoria, BC, Canada, 2014.

14. Turnbull, K.F.; NCHRP. Synthesis of Highway practice 213. In Effective Use of Park-and-Ride Facilities; National Academy Press: Washington, DC, USA, 1995.

15. De Jong, M.; Geerlings, H. Roadmap for Infrastructure Appraisal; DUP Science: Delft, The Netherlands, 2004.

16. Hamid, N.A.; Mohamad, J.; Karim, M.R. Travel behaviour of the park and ride users and the factors influencing the demand for the use of the park and ride facility. In Proceedings of the EASTS International Symposium on Sustainable Transportation Incorporating Malaysian Universities Transport Research Forum Conference 2008 (MUTRFC08), UTM, Skudai, Johor, Malaysia, 12-13 August 2008.

17. Abdullah, A.Z. Predicting the impact of demand-and supply-side measures on bus ridership in Putrajaya, Malaysia. J. Public Transp. 2006, 9, 4 . 
18. Putrajaya, P.; World's First Intelligent Garden City. Perbadanan Putrajaya. Available online: http://www.putrajaya.gov.my/m_ tourist/green_city/ (accessed on 22 October 2013).

19. Borhan, M.N.; Rahmat, R.A.A.; Ismail, R.; Ismail, A. Prediction of travel behavior in Putrajaya, Malaysia. Res. J. Appl. Sci. Eng. Technol. 2011, 3, 434-439.

20. Transportation Research Board; Morpace International. A Handbook for Measuring Customer Satisfaction and Service Quality; Transportation Research Board: Washington, DC, USA, 1999; Volume 47, p. 030906323X.

21. Norhisham, S.; Sidek, L.M.; Beddu, S.; Usman, F.; Basri, H.; Katman, H. Awareness and Level of Usage for Park and Ride Facilities in Putrajaya, Malaysia. In Proceedings of the EngCon 2012, Engineering Conference, Kuching, Malaysia, 10-12 July 2012.

22. Nor, N.G.M.; Nor, A.R.M. Predicting the impact of demand and supply side measures on bus ridership in Putrajaya, Malaysia. J. Public Transp. 2006, 9, 5.

23. Hamsa, A.A.K. Users'perceptions on parking utilization pattern at park-and-ride facility in putrajaya sentral. J. Archit. Plan. Constr. Manag. 2010, 1, 1.

24. Borhan, M.N.; Syamsunur, D.; Akhir, N.M.; Yazid, M.R.M.; Ismail, A.; Rahmat, R.A. Predicting the use of public transportation: A case study from Putrajaya, Malaysia. Sci. World J. 2014, 2014, 784145. [CrossRef] [PubMed]

25. Adnan, S.S.; Hamsa, A.A.K. Evaluating the parking demand at park and ride facility at Putrajaya public transportation terminal. In Proceedings of the 2013 International Conference of Eastern Asia Society for Transportation Studies (EASTS), Taipei, Taiwan, 9-12 September 2013. Eastern Asia Society for Transportation Studies.

26. Memon, I.A.; Napiah, M.; Hussain, M.A.; Hakro, M.R. Influence of factors to shift private transport users to Park-and-Ride service in Putrajaya. In Engineering Challenges for Sustainable Future, Proceedings of the 3rd International Conference on Civil, Offshore and Environmental Engineering, ICCOEE 2016, Kuala Lumpur, Malaysia, 15-17 August 2016, 1st ed.; Wan Abdullah Zawawi, N.A., Ed.; CRC Press: London, UK, 2016; p. 566.

27. Ahmed, M.I.; Saima, K.; Noman, S.; Madzlan, B.N. Factors that influence travelers' willingness to use or not park-and-ride service in putrajaya and karachi Cbd. PalArch's J. Archaeol. Egypt/Egyptol. 2021, 18, 720-734.

28. Lam, W.H.K.; Holyoak, N.M.; Lo, H.P. How Park-and-Ride Schemes Can Be Successful in Eastern Asia. J. Urban Plan. Dev. 2001, 127, 63-78. [CrossRef]

29. Adnan, S.; Alyia, S.A.; Hamsa, K.; Azeez, A. Users' perceptions on parking utilization pattern at park-and-ride facility in Putrajaya Sentral. J. Archit. Plan. Constr. Manag. 2011, 1, 147-165.

30. Borhan, M.N.; Ismail, A.; Rahmat, R.A.O.; Ambak, K. Effect of transport policies to shifting private car users to park-and-ride in Putrajaya, Malaysia. Aust. J. Basic Appl. Sci. 2011, 5, 303-308.

31. KonSULT. KonSULT I Policy Guidebook. University of Leeds. Available online: http://www.konsult.leeds.ac.uk/pg/35/ (accessed on 20 February 2017).

32. Memon, I.A. Factors Influencing Travel Behaviour and Mode Choice among Universiti Teknologi Malaysia Employees. Master's Thesis, Department of Urban and Regional Planning, Faculty of Built Environment, Universiti Teknologi Malaysia, Johor Bahru, Malaysia, 2010.

33. Turnbull, K.; Evans, J.; Levinson, H. Park-and-Ride/Pool: Traveller Response to Transport System Changes; Transit Cooperative Research Program Report; The National Academies Press: Waashington, DC, USA, 2004; Volume 95.

34. Morrall, J.; Bolger, D. Park-and-Ride: Canada's Most Effective TDM Strategy. In Proceedings of the Cost Effectiveness through Innovation, 1996 TAC Annual Conference, Charlottetown, PE, Canada, 6-9 October 1997.

35. Parkhurst, G. Influence of bus-based park and ride facilities on users' car traffic. Transp. Policy 2000, 7, 159-172. [CrossRef]

36. Memon, I.A.; Madzlan, N.; Talpur, M.A.H.; Hakro, M.R.; Chandio, I.A. A Review on the Factors Influencing the Park-and-Ride Traffic Management Method. Appl. Mech. Mater. 2014, 567, 663-668. [CrossRef]

37. Wright, C.; Egan, J. De-marketing the car. Transp. Policy 2000, 7, 287-294. [CrossRef]

38. Duncan, M.; Christensen, R.K. An analysis of park-and-ride provision at light rail stations across the US. Transp. Policy 2013, 25, 148-157. [CrossRef]

39. Olsson, A.-L.L. Factors That Influence Choice of Travel Mode in Major Urban Areas. Ph.D. Thesis, Department of Infrastructure, Royal Institute of Technology, Stockholm, Sweden, 2003. Available online: https://www.diva-portal.org/smash/get/diva2: 7556/FULLTEXT01.pdf (accessed on 18 April 2016).

40. Shaharyar, B.; Ahmed, M.I.; Saima, K.; Noman, S. Predicting the use of public transportation service: The case study of karachi circular railway. PalArch's J. Archaeol. Egypt/Egyptol. 2021, 18, 4736-4748.

41. Brohi, S.; Kalwar, S.; Memon, I.A.; Ghaffar, A. Using the Theory of Planned Behavior to Identify the Behavioral Intention to use Public Transportation Service: The Case Study of Karachi Circular Railway. Int. J. Emerg. Technol. 2021, 12, 6.

42. Papagiannakis, A.; Baraklianos, I.; Spyridonidou, A. Urban travel behaviour and household income in times of economic crisis: Challenges and perspectives for sustainable mobility. Transp. Policy 2018, 65, 51-60. [CrossRef]

43. Kaffashi, S.; Shamsudin, M.N.; Clark, M.S.; Sidique, S.F.; Bazrbachi, A.; Radam, A.; Adam, S.U.; Rahim, K.A. Are Malaysians eager to use their cars less? Forecasting mode choice behaviors under new policies. Land Use Policy 2016, 56, 274-290. [CrossRef]

44. Memon, I.A.; Kalwar, S.; Sahito, N.; Qureshi, S.; Memon, N. Average Index Modelling of Campus Safety and Walkability: The Case Study of University of Sindh. Sukkur IBA J. Comput. Math. Sci. 2020, 4, 37-44. [CrossRef]

45. Ajzen, I. The theory of planned behavior. Organ. Behav. Hum. Decis. Process. 1991, 50, 179-211. [CrossRef] 
46. Fujii, S.; Kitamura, R. What does a one-month free bus ticket do to habitual drivers? An experimental analysis of habit and attitude change. Transportation 2003, 30, 81-95. [CrossRef]

47. Ajzen, I.; Fishbein, M. Understanding Attitudes and Predicting Social Behaviour; Pearson: New York, NY, USA, 1980.

48. Ding, C.; Chen, Y.; Duan, J.; Lu, Y.; Cui, J. Exploring the Influence of Attitudes to Walking and Cycling on Commute Mode Choice Using a Hybrid Choice Model. J. Adv. Transp. 2017, 2017, 1-8. [CrossRef]

49. Kaewkluengklom, R.; Satiennam, W.; Jaensirisak, S.; Satiennam, T. Influence of psychological factors on mode choice behaviour: Case study of BRT in Khon Kaen City, Thailand. Transp. Res. Procedia 2017, 25, 5072-5082. [CrossRef]

50. Dharmowijoyo, D.B.; Susilo, Y.O.; Karlström, A.; Adiredja, L.S. Collecting a multi-dimensional three-weeks household time-use and activity diary in the Bandung Metropolitan Area, Indonesia. Transp. Res. Part A Policy Pract. 2015, 80, 231-246. [CrossRef]

51. Jariyasunant, J. Improving Traveler Information and Collecting Behavior Data with Smartphones. Ph.D. Thesis, University of California, Berkeley, CA, USA, 2012. Available online: http://search.proquest.com/docview / 1081704510 ?accountid=47520 (accessed on 23 December 2016).

52. Louviere, J.J.; Hensher, D.A.; Swait, J.D. Stated Choice Methods: Analysis and Applications; Cambridge University Press: Cambridge, MA, USA, 2000. 